\title{
From Pink Frilly Dresses to 'One of the Boys': A Social-Cognitive Analysis of Gender Identity Development and Gender Bias
}

\author{
May Ling Halim, Diane N. Ruble, and David M. Amodio* \\ New York University
}

\begin{abstract}
In middle childhood, many girls go through a curious metamorphosis, in which their earlier embrace of all-things-feminine appears to transform into an identity as a tomboy. We believe this striking shift, observed in girls but not boys, signifies a critical development in children's sociocognitive functioning, with implications for their understanding of gender as it relates to their identity and their social relationships. In this article, we review the evidence for this identity shift and present a theoretical account that integrates ideas from social cognition and social development. We argue that this identity shift involves the emergence of public regard and status awareness, with concurrent increases in the complexity with which knowledge associated with gender categories is represented in the mind. We then posit that these changes have important implications for the developmental trajectory of implicit and explicit gender attitudes and stereotypes, and we present a set of predictions generated by our theoretical analysis.
\end{abstract}

Gender is one of the earliest learned and most influential social identities throughout the lifespan (Bem, 1993). Gender identity is usually seen as relatively stable; except in rare circumstances, an individual remains a male or female for life despite contextually-based shifts in certain features, such as the salience of gender identity or the display of gendertyped behaviors (Deaux \& LaFrance, 1998). Yet, gender identities can change. According to social identity theory, individuals seeking to maximize their self-esteem may move from identifying with a low-status social group to a higher-status one if boundaries between the groups are permeable (Tajfel \& Turner, 1979, 1986). Given the status disparity between men and women (Deaux \& LaFrance, 1998; Rudman \& Glick, 2008), it is interesting to ask whether this social identity principle applies to gender.

Childhood is an especially exciting time to view gender through the lens of social identity principles. It is during this period that individuals first learn about gender categories, the boundaries of those categories, and their permanence (Ruble, Martin, \& Berenbaum, 2006). Gender is also extremely salient to most children in their everyday lives (Ruble et al., 2006). Although basic self-categorization into a gender group may not normally change after preschool, gender identity consists of multiple dimensions that may be flexible, such as the centrality of gender to one's self-concept or how typical one feels (Halim \& Ruble, 2010; Tobin et al., 2010). Moreover, whereas gender identity during the preschool years primarily connects to specific gender-typed activities and interests (e.g., dolls and princesses versus trucks and superheroes), gender identity during middle childhood takes on larger meanings in terms of interpersonal relationships, intergroup evaluations, and one's place in society. During the same time period, substantial 
advancements in children's social-cognitive processes occur that may motivate and enable social identity change.

In this paper, we suggest that aspects of gender identity have the potential to become dynamic because of two important social cognitive developments that occur between preschool and middle childhood: (i) changes in children's awareness of the variation that exists in evaluative standpoints toward social categories (public regard); and (ii) changes in children's representations of gender categories (see Table 1). We describe how these two sets of social-cognitive processes contribute to gender identity changes and then suggest how this social-cognitive framework can inform a wider range of identity-relevant phenomena, such as intergroup beliefs and attitudes. We begin our review with an illustrative phenomenon that captures the kind of gender identity-relevant change that appears to take place during this time period.

\section{An Illustrative Phenomenon: The Pink Frilly Dress}

Social-cognitive processes underlying shifts in gender identity are manifested in one particularly intriguing phenomenon. Recently, preschool- and kindergarten-aged girls seen flitting around in pink, frilly dresses have caught the attention of both the media and psychologists (e.g., Bailey, 2008; Bates, 2009; Orenstein, 2010; Ruble, Lurye, \& Zosuls, 2007a; Ruble et al., 2007b). Glittery chiffon peeks out of their winter jackets even on the coldest of days. These girls not only love pink - they demand to wear pink and refuse to wear pants nearly every single day and for every occasion, even when inconvenient and inappropriate, such as when they have run out of clean pink clothes or when embarking on a day of strenuous outdoor activities. (Halim et al., forthcoming; Ruble et al., 2007a). This phenomenon - which we call 'PFD' for 'pink frilly dress' - is striking, seen in $74 \%$ of the 3- to 4-year-old girls in a recent empirical study (Halim et al., forthcoming). Interestingly, PFD does not seem to be simply the result of parent socialization; many parents report being forced to negotiate with and often yield to their daughters on the issues of wearing such clothing (Halim et al., forthcoming). Moreover, PFD was found to be linked to girls' positive evaluation of their gender identity and with a greater understanding that gender is relatively stable over time (Halim et al., forthcoming),

Table 1 Framework of social cognitive developmental changes affecting gender identity shifts

\section{Processes}

\begin{tabular}{ll}
\hline Standpoints toward gender categories & Changing representations of gender \\
\hline Increasing awareness of public regard & Shift from rigidity to flexibility in gender category \\
Increasing awareness of higher male status & distinctions \\
Increasing awareness of discrimination against & Understanding of gender constancy \\
women & More advanced classification skills \\
More complex and nuanced theory of mind & Change in essentialistic thought \\
Neurological development & Increase in recognizing heterogeneity within gender \\
Maturation of medial prefrontal cortex & categories \\
& Increasing understanding of the dimensional nature \\
& of traits \\
& Better understanding of individual differences, or \\
& within-category variability \\
& More use of subgrouping
\end{tabular}


suggesting that PFD reflects the developmental process of girls' understanding and embracing their female gender identity. These girls appear to love being girls and they want to communicate that symbolically through their clothing.

Curiously, a very different type of behavior is seen during elementary school when the girls are a few years older. No longer is PFD the norm; only approximately $30-40 \%$ of girls in middle childhood describe themselves as traditional girls or as having primarily femaletypical interests (England, Martin, Dinella, \& Leonard, 2011; Jannone, Halim, Greulich, Lurye, \& Ruble, forthcoming). Instead, in an apparent $180^{\circ}$ turnabout, 'tomboyism' becomes quite common, with some girls eschewing the PFD they embraced just a few years earlier. Several retrospective studies have revealed that approximately one-third to three-quarters of women recall being tomboys in middle childhood (Burn, O'Neil, \& Nederend, 1996; Hyde, Rosenberg, \& Behrman, 1977; Morgan, 1998; Plumb \& Cowan, 1984). Studies of elementary school children have observed similar rates of prevalence, with approximately one-third to one-half of girls labeling themselves as tomboys (Dinella \& Martin, 2003; Jannone et al., forthcoming). Indeed, girls in elementary school show increasing interest in masculine activities and behaviors - they like to play more sports, wear pants, talk and act like boys, and play with male-typed toys (Bailey, Bechtold, \& Berenbaum, 2002; Paechter \& Clark, 2007; Sandberg \& Meyer-Bahlburg, 1994). Some research suggests that girls also develop an active aversion to feminine activities and interests (Carr, 1998), and they may actively shun pink objects and female-typed activities (McHale, Shanahan, Updegraff, Crouter, \& Booth, 2004). As tomboys, they report an adamant refusal to wear skirts or dresses (Paechter \& Clark, 2007). Hence, these normative shifts suggest major changes in the gender identity and attitudes of many girls in a relatively short period of time.

Do boys show a similar change in their gender identity and attitudes? The evidence suggests that they do not. In early childhood, boys, like girls, show strong gender-typed rigidity during preschool and kindergarten, expressed in male-typical interests and forms of play (see Ruble \& Martin, 1998). However, in elementary school, at the time when girls begin to shift away from a highly feminine gender identity, most boys remain steadfastly masculine and interact mainly with other boys (Maccoby, 1998; Ruble \& Martin, 1998). ${ }^{1}$ In a review of the gender literature, Ruble et al. (2006) concluded that, in middle childhood, boys tend to be more rigid in their stereotypic toy and activity preferences than girls.

What explains this curious shift in gender identity and related behaviors among many girls but not boys between early (preschool) and middle childhood (elementary school)? In the following section, we examine social-cognitive developmental processes that can affect social identity, integrating theoretical ideas from adult social and cognitive psychology with developmental psychology (Pomerantz \& Newman, 2000).

\section{Standpoints Toward and Representation of Gender Categories: A Proposed Social-Cognitive Framework for Gender Identity Change}

We suggest that identity-relevant changes, such as those illustrated by the PFD to tomboyism shift, reflect two general sets of concurrent developments in how children think about themselves and others. First, they begin to view social categories from multiple standpoints, including from the viewpoints of others, not just from their own internal perspectives (e.g., Moretti \& Higgins, 1999). This means, for example, that girls and boys become increasingly aware of the differential status ascribed to males and females in society, and they find themselves included in either the high or low status group. At the 
same time, in step with continuing neural development, a child's capacity for appreciating another person's unique point of view (Theory of Mind) increases dramatically (Saxe, Carey, \& Kanwisher, 2004). Second, dramatic changes in how gender is represented, both at the group and individual level, occur during this time period (Olson \& Dweck, 2008; Ruble \& Goodnow, 1998). Hence, we will argue that the PFD-tomboy shift we are describing reflects two powerful sets of social-cognitive developments: an awareness of differing standpoints toward gender categories and changing representations of gender.

\section{Standpoints toward gender categories}

We propose that one way to understand the shift from PFD to tomboy is to consider children's changing capacity to view gender from multiple standpoints. In this section, we examine the nature of these changes as reflected in two different, but related areas of research: the development of public regard and theory of mind.

The development of public regard. Public regard refers to the awareness that other people may evaluate one's group and hold it in high or low esteem, and this awareness is recognized as a key component of social identity (Ashmore, Deaux, \& McLaughlin-Volpe, 2004; Sellers, Smith, Shelton, Rowley, \& Chavous, 1998). To date, theories of gender identity development have not integrated research on public regard; yet we believe such integration is critical for explaining dramatic observed shifts in gender identity and attitudes. For example, research on group hierarchies has found that adult members of lowstatus groups, who are presumably aware of the negative public regard toward their group, tend to exhibit ambivalent attitudes toward members of their own group and sometimes show positive implicit attitudes toward the high-status outgroup (see Dasgupta, 2004; Jost, Banaji, \& Nosek, 2004; Lane, Mitchell, \& Banaji, 2005). In one study, the implicit and explicit attitudes of college students from various lower-status groups were assessed (Rudman, Feinberg, \& Fairchild, 2002). These students took an Implicit Association Test and reported on a feelings thermometer how warm or cold they felt toward their own group and toward the high status group. These members of lower-status groups were, from higher to lower status, as rated by themselves and others, Jews, Asians, overweight people, and poor people. Results showed that the lower the group status, the less positive was the implicit ingroup bias. Adult members of low-status groups also sometimes show outgroup favoritism (although this is not always the case: see Lane et al., 2005). In one study, Latino and Asian American college students tended to choose White partners over members of their own ethnic groups when signing up for an ostensible psychology experiment (Jost, Pelham, \& Carvallo, 2002).

Other research suggests that the experience of being a member of a low-status group motivates changes in one's identity that involve distancing oneself from the low-status group and/or associating more strongly with the high-status group, in combination with other strategies for improving self-esteem (Brewer \& Brown, 1998; Tajfel \& Turner, 1986). Indeed, in one qualitative study, women reported that they became tomboys because they were aware of and desired the advantages conferred on masculinity by society (Carr, 1998). Thus, it appears that the gender identity shifts reflected in the PFDto-tomboy phenomenon may be triggered by an emerging sense of public regard. Given the status differences associated with gender, this trigger operates very differently among girls than among boys.

Several studies have examined perceptions of gender status in children. Children aged 6 to 12 have been found to perceive masculine jobs as more important, lucrative, 
difficult, and higher in status compared with feminine jobs, and these perceived differences were greater among the older children (Liben, Bigler, \& Krogh, 2001; Teig \& Susskind, 2008). Similarly, Neff, Cooper, and Woodruff (2007) found that children aged 7 to 15 tended to believe that men have more power, influence, status, and respect than did women in business and politics, a difference that was also greater among the older children. Hence, findings in the extant literature are consistent with the idea that the awareness of status differences associated with public regard emerges during middle childhood years, although questions remain about public regard in early childhood.

Children also become increasingly aware of gender discrimination in middle childhood (Verkuyten, Kinket, \& van der Wielen, 1997), and this likely coincides with the development of public regard. For example, when asked why there has never been a female president of the United States, 10-year-olds are more likely to cite gender discrimination than 5-year-olds (Bigler, Arthur, Hughes, \& Patterson, 2008). In other research (Brown \& Bigler, 2004), children were given scenarios in which a teacher evaluated either a female or male student more positively than the other. When children learned that discrimination might be likely (e.g., when told, 'Mr. Franks almost always gives boys higher grades than girls on their stories'), children aged 5 to 7 were nevertheless more likely to attribute the evaluation to the child's ability or effort rather than to discrimination, relative to children aged 8 to 10 . Thus, a substantial number of children in middle childhood are aware of gender discrimination, and this awareness increases with age.

Theory of mind. The emerging ability to view social categories from another standpoint in middle childhood may reflect more basic-level developments in Theory of Mind (ToM). ToM refers to the belief that other people possess their own unique perspectives, mental states, desires, emotions, beliefs, and intentions. Different components of ToM appear to develop over time. Much of the research on ToM in children has examined the degree to which children understand that another person may have a unique perspective on objects (Wellman, Cross, \& Watson, 2001). For example, at around 4 years of age, children recognize that two people who see the same object from different perspectives will have different visual experiences (Flavell, 1978; Masangkay et al., 1974), as well as different beliefs about the object (Astington, Harris, \& Olson, 1988; Gopnik \& Astington, 1988).

By around the age of 7 or 8 years, children begin to understand that a stimulus, seen or heard in exactly the same way, may be interpreted differently (Wainryb, Shaw, Langley, Cottam, \& Lewis, 2004). This ability is called interpretative ToM (Carpendale \& Chandler, 1996; Lalonde \& Chandler, 2002; Ross, Recchia, \& Carpendale, 2005). Children aged 7 to 9 also increasingly understand that people can have different trains of thought about the same stimuli (Eisbach, 2004). Thus, if children have positive conceptions of their own gender, understanding that others may have different, even negative, conceptions of their own gender would facilitate the development of public regard.

A growing body of neuroscience research corroborates the idea that changes in the development of children's brains may relate to theory of mind and the emergence of public regard (Crone, 2008; Liu, Sabbagh, Gehring, \& Wellman, 2009; Saxe et al., 2004). Neuroimaging studies of adults suggest that the processes of ToM, categorical person perception, and group perception are associated with activity in regions of the medial prefrontal cortex (mPFC). In particular, the $\mathrm{mPFC}$ has been linked to a range of processes related to ToM such as understanding that there are false beliefs, mentalizing, and person perception (Amodio \& Frith, 2006; Frith \& Frith, 1999), all of which are conceptually related to the awareness of public regard. 
One particular within-subjects fMRI study had volunteers look at three types of cartoons (ToM, non-ToM, and control) and to consider the meaning of each cartoon silently (Gallagher et al., 2000). An example ToM cartoon depicted a scientist who had just used a telescope with dark, inky rings around his eyes looking wonderingly at two colleagues, snickering with each other, with large markers in hand. A non-ToM cartoon depicted workers at an assembly line. A control cartoon was a jumbled picture of different objects (a violin player, a trailer, and a unicorn). Activation of the MPFC was greater in the theory of mind task than in the non-theory of mind and control tasks. Interestingly, the anterior regions of the mPFC linked to ToM (e.g., BA 10) are among the slowest regions of the brain to form, and they continue to develop into late childhood (Casey, Galvan, \& Hare, 2005a; Casey, Tottenham, Liston, \& Durston, 2005b; Sowell et al., 2004). Hence, the neural developments from ages 3 to 10 associated with ToM appear to correspond with the emergence of public regard.

In sum, this research suggests that a confluence of developmental changes in the mind and brain from early to middle childhood contribute to children's ability to take the standpoint of others in viewing social categories. As children's brains mature and their theory of mind becomes more complex, children may begin to understand that males are a higher status group than females and that gender discrimination can occur. These changes suggest a mechanism by which the gender identity of girls may shift in ways that do not occur for boys. Girls may turn toward masculinity, whereas boys may remain staunchly masculine.

\section{Changing representations of gender}

An important second set of developmental changes - representations of gender - provides the vehicle for a shift in gender identity because they allow social identity movement without major violations of social norms. In this section, we examine two fundamental changes in children's understanding of gender categories: (i) a shift from rigidity to flexibility in making gender category distinctions, and (ii) an increase in recognizing heterogeneity within gender categories.

Shift from rigidity to flexibility in gender category distinctions. One well-documented change in the literature on gender development concerns shifts in the rigidity versus flexibility of gender norms. By about 3 years of age, children typically know some gender stereotypes (Miller, Lurye, Zosuls, \& Ruble, 2009), but at approximately 7 years of age, children's acceptance of stereotypes as inflexible or morally right declines, even though their knowledge of stereotypes continues to increase (Huston, 1983; Ruble et al., 2006). For example, in a longitudinal study following children annually from age 5 to 10 , interviewers read children a list of behaviors and traits (e.g., 'There are children who are very strong and can lift heavy things', 'There are people who like to look beautiful and to please others') and asked children who they think is like that (Trautner et al., 2005). Children showed the highest level of rigidity (i.e., responding 'only' females or 'only' males) at 5 or 6 years of age and then a dramatic increase in flexibility (i.e., responding that the item could apply to both females and males) beginning 2 years later. In short, older children recognize that there are many similarities between boys and girls.

One additional noteworthy finding in the Trautner et al. (2005) study is that analyses of individual differences in stereotyping indicated that children followed the same developmental trajectory of rigidity followed 2 years later by flexibility, regardless of variations in when rigidity reached its peak or what level it reached. These findings suggest that 
cognitive developmental factors influence this shift toward flexibility, even if socio-cultural factors, such as how much families emphasize gender equality, influence how early rigidity emerges and how extreme it gets. Although the exact cognitive precursors to this shift from rigidity to flexibility are unknown, research has highlighted a few possibilities.

First, by 5 to 7 years of age, most children achieve an understanding that, despite superficial changes, such as a girl's short haircut, gender remains permanent (gender constancy; Szkrybalo \& Ruble, 1999). This understanding has been linked to increased flexibility in gender-typed beliefs and attitudes. For example, in one study, when asked, 'Is it wrong for boys to wear nail polish?' children who better understood the permanence of gender more often answered, 'No,' and were more willing to be friends with a boy who wore nail polish (Ruble et al., 2007b). Second, children in middle childhood increasingly improve in their ability to simultaneously classify a person across multiple dimensions (Piaget, 1965), such as across gender and race, and this ability has been linked to less rigid stereotyping (Bigler, 1995; Bigler \& Liben, 1992). Third, there are important changes in children's essentialistic thought between early and middle childhood (Gelman \& Taylor, 2000). That is, although younger children can understand that there are some essential non-observable features that distinguish boys and girls, older children view such features as more diagnostic of category membership than outward appearances and behaviors. Once children recognize that appearance and behaviors are less essential to differentiating boys and girls, they can be more flexible in their reactions to gender norm violations. Thus, one possible way to understand the shift from PFD to tomboyism is that cognitive developmental processes between preschool and middle elementary school enable children to represent the attributes of males and females in more flexible terms, such that they feel more comfortable deviating from gender norms. In the case of girls as tomboys, it may simply become more acceptable to themselves and their peers to wear pants and play soccer.

Increase in recognizing heterogeneity within gender categories. Several lines of evidence also suggest that, as they move from early to middle childhood, children view individuals in more complex ways, allowing an appreciation of heterogeneity within a category. First, children's understanding of the nature of personal attributes changes. In early childhood, children understand traits as categories (e.g., 'shy' or 'not shy') (Heyman \& Gelman, 1999, 2000), whereas during elementary school, they increasingly view traits as dimensional in nature (e.g., 'a little bit shy' or 'very shy') (Gonzalez, Zosuls, \& Ruble, 2010). Thus, girls learn that they can be only a little bit or a lot girly and still be considered girls. Coupled with an understanding that gender is relatively permanent (Szkrybalo \& Ruble, 1999), girls can feel secure in their gender identity without adhering to a prototype.

Second, children increasingly understand individual differences as they move from early to middle childhood (Alvarez, Ruble, \& Bolger, 2001). Younger children are less likely to recognize that there can be individual variation in how gender-typed individual children might be within gender categories (Martin, 1989). For example, in one study, when asked if a target child would like to play with dolls or trucks, younger children's judgments were based on categorical information (whether the child was a boy or a girl). For children 8 years and older, however, the target child's individual preferences mattered, such that a target boy described as liking kitchen sets was judged to also like playing with dolls (Martin, Woods, \& Little, 1990). Thus, for younger children, being a boy and having masculine characteristics appear to be equivalent, whereas older children understand that some girls differ from other girls and some boys differ from other boys. Thus, by middle childhood, girls can still consider themselves members of the female category, 
even if they prefer male-typical activities. A parallel in the adult impression formation literature involves the same kind of process. Among adults, given information-processing limits and a complex social environment, the dominant mode of impression formation relies on categorical thinking, or group stereotypes, and this involves automatic processing (Fiske \& Neuberg, 1990). However, in the appropriate motivational context, individuating information (like, 'She likes to eat carrots') can encourage a controlled, more attribute-based, form of processing (Fiske \& Neuberg, 1990).

Third, because children in middle childhood increasingly recognize within-group variability among gender groups, they may be more able than younger children to form gender subgroups. The process of subgrouping refers to a person's organization of a superordinate group into clusters of individuals based on their similarities and differences (Hornsey \& Hogg, 2000; Richards \& Hewstone, 2001). To our knowledge, research has not yet examined children's spontaneously-generated gender subgroups. However, one study on late adolescents found that the top-listed female subgroups included 'prissy girl' and 'athlete' (Eckes, Trautner, \& Behrendt, 2005). Research from the adult literature has found similar gender subgroups (e.g., Noseworthy \& Lott, 1984; Vonk \& Olde-Monnikhof, 1998), which can have distinct sets of stereotypes (e.g., Deaux \& LaFrance, 1998; Vonk \& Ashmore, 2003). Other findings also suggest that subgrouping may function as a buffer in self-stereotyping (Steele, 2003). In this study, girls exhibited gender stereotypes having to do with math abilities with regard to adults (they associated men with math), but not with regard to children (they associated math with both boys and girls). Steele (2003) proposed that girls subgroup themselves from the female superordinate group, which may explain, in part, why girls and boys do equally well on math, but men outperform women. Hence, we speculate that tomboys and girly-girls are subgroups formed by girls during elementary school that can buffer tomboys from the effects of negative beliefs about female inferiority to males.

Summary. Children's representations of gender change from early to middle childhood in a way that corresponds to the PFD-to-tomboy phenomenon. During this timeframe, children's conceptualization of gender norms increases in flexibility, making it possible for girls to 'blur' the boundaries between boys and girls and thus feel freer to assume more boy-like characteristics. At the same time, a greater understanding of within-gender category heterogeneity, in terms of the dimensionality of traits and awareness of individual differences, makes it possible for a girl to be relatively low on 'girliness' but still feel like she belongs to the female gender category. Moreover, these more complex gender category representations allow children to form gender subgroups that further facilitate shifts in gender identity.

\section{A Social-Cognitive Framework for Gender Identity Change}

We have used an illustration from the developmental literature to show how social-cognitive processes can underlie shifts in a social identity. Specifically we posited that the concurrent developments in (i) children's increasing capacity to think about social categories from another standpoint, and in (ii) children's more complex representations of social categories may jointly influence the shift from PFD to tomboyism in girls, and also influence the staunch adherence to masculinity in boys, from early to middle childhood. Additionally, we have argued that neural changes during this time contribute to more sophisticated theory of mind, which corresponds to an increased ability to take the standpoint of others in viewing social categories. This advance in children's social cognition, 
in turn, contributes to increasing awareness of public regard, including the awareness of gender status differences and gender discrimination, which all serve together as a trigger to a shift in social identity. During the same developmental period, increases in the complexity of gender category representations, including stereotype flexibility, within-category heterogeneity, and subgrouping, provide a vehicle for change. In short, so far, our social-cognitive analysis has been used to explain an intriguing illustration of the implications of basic developmental processes for social identity change, specifically from PFD to tomboy. We believe this analysis can be applied to a broad set of sociocognitive processes beyond identity shifts. Thus, in a brief, final section, we consider in what ways our social-cognitive analysis might generate some novel predictions regarding developmental changes in intergroup attitudes and beliefs.

\section{Implications for Gender-Related Intergroup Attitudes and Beliefs}

What are the implications of our social-cognitive analysis for developmental changes in how children perceive and feel about boys and girls? What happens to girls' ingroup positivity when they become aware of lower public regard and potential gender discrimination? Do boys increase in outgroup derogation and prejudice? In addition, given the focus of much of contemporary social psychological research on implicit versus explicit components of attitudes and stereotypes, it makes sense to ask how the social-cognitive analysis might apply to this distinction. Do these implicit and explicit components diverge or converge during development? In this section, we discuss the implications of our theoretical analysis for changes in children's explicit and implicit gender associations, as they relate to stereotypes and cognitive and affective components of attitudes (see Amodio \& Mendoza, 2010 for a full discussion of components of stereotypes and attitudes).

\section{Predictions for explicit gender stereotyping and attitudes}

According to social identity theories, children's understanding that they belong to one social group and not another should initiate a number of identity validation processes (Tajfel \& Turner, 1979), one of which is to view one's own sex (i.e., the ingroup), more favorably. Our social-cognitive analysis suggests that, prior to the awareness of public regard, both boys and girls should show this ingroup bias, and stereotypes and attitudes should be relatively consistent. Indeed, for both sexes, research shows that gender stereotypes in early childhood are very positive for the ingroup (e.g., Powlishta, Serbin, Doyle, \& White, 1994), accompanied by gender attitudes that reflect strong ingroup positivity (Yee \& Brown, 1994).

By middle elementary school, the increased complexity of gender representations, in combination with increased public regard, should lead to more nuanced attitudes towards both the gender ingroup and outgroup as well as to more balanced stereotypes, especially for girls. For stereotypes, prior research has shown, as predicted, that the positivity bias declines with age (Martin \& Ruble, 2009). It is not yet clear if this decline is the same for boys and girls. Surprisingly, however, if anything, girls have been found to show more biased (anti-boy) explicit intergroup evaluations and stereotypes overall (Zosuls et al., 2011), perhaps because of the play and interpersonal styles among most boys, which many girls find aversive (Ruble et al., 2006), or because different subgroups of girls (e.g., tomboys versus girly girls) may respond differently. Indeed, tomboys have been found to possess explicit positive evaluations of boys (in regards to the adjectives fun, great, important, dumb, annoying, boring, with the negative adjectives reverse-scored), 
whereas traditional girls have been found to possess more neutral explicit evaluations (Jannone et al., forthcoming). In the same study, girls in all subgroups expressed positive explicit evaluations of girls, but the degree of positivity was stronger among traditional girls than it was among tomboys.

In contrast to stereotypes and cognitive aspects of attitudes, there has been little research about developmental trends in the affective aspects of attitudes - that is, how children feel about males and females. In one recent study, Zosuls et al. (2011) explicitly asked about positive and negative feelings and found ingroup bias for positive feelings only; neither boys nor girls felt negatively toward the outgroup, at least not explicitly. Future research involving direct comparisons across age, attitudes, and stereotypes is needed, including comparisons of these components with awareness of public regard. Of particular interest is the possibility that a girl's personal evaluation of females may become dissociated from her perceived (negative) public regard for her gender group a dissociation observed in adults for ethnic identity (e.g., Wiley, Perkins, \& Deaux, 2008).

\section{Predictions for implicit gender stereotyping and attitudes}

Our social-cognitive framework also has implications for the development of implicit gender associations. Here, we invoke cognitive neuroscience models of intergroup bias to develop our predictions (e.g., Amodio, 2008; Amodio \& Ratner, 2011). Implicit affective attitudes are believed to involve subcortical neural structures, such as the amygdala (Amodio, Harmon-Jones, \& Devine, 2003), a structure that develops early. By contrast, semantic forms of implicit bias involve neocortical structures in the brain, such as the lateral temporal lobe and the posterior prefrontal cortex (Gabrieli, 1998), which are still developing in young children and grow until early adulthood (Casey et al., 2005a).

Accordingly, we predict that implicit affective associations should represent the earliest form of implicit gender bias in early childhood, similar to early forms of implicit racial or nationality bias in young children (Dunham, Baron, \& Banaji, 2006). By comparison, implicit conceptual associations, which comprise stereotypes, are expected to be weaker and relatively less well-formed. Instead, we might observe simple conceptual associations picked up from one's social environment (Olson \& Fazio, 2004), and these may or may not relate to children's personal affective responses and behavior. For example, children at this age may learn to repeat adults' suggestions that girls are good and boys are bad, without really internalizing this attitude. Indeed, in a child version of the IAT, children were found to associate girls with 'good' and boys with 'bad' (Cvencek, Greenwald, \& Meltzoff, 2011). Finally, given the relatively simplistic representations of gender in early childhood, we would not predict strong implicit stereotyping effects at this age (with the exception of associations with affect-laden trait attributes, such as warm and strong; Rudman, Greenwald, \& McGhee, 2001). Thus, we predict that young children would show strong implicit positive affective associations toward their own gender group, but weak implicit affective associations with the gender outgroup and relatively weak implicit stereotype associations with either group. For example, in a potential experiment on implicit affective associations, looking at pictures of girls may facilitate girls' categorization of cartoon happy faces, or viewing a picture of a girl before an unfamiliar object (like a Chinese pictograph) may cause girls to associate that object with happy and fun feelings. However, for a girl, looking at pictures of boys may have no real effect on these types of implicit affective measures. As an example of weak implicit stereotype associations, in a potential 
experiment, children may show no different reaction times when linking concepts like 'math' or 'verbal' with either girls or boys.

The transition to middle childhood brings with it an elaborated semantic network and capacity for implicit conceptual associations. At this age, we predict that implicit conceptual 'cognitive' attitudes should reflect internalized preferences, as in adults. These implicit conceptual cognitive evaluations should most likely match affect-based associations, as in adults (e.g., Phelps et al., 2000). Although the correspondence between affective and cognitive forms of implicit gender attitudes has not been studied, it is also possible that these forms of bias may diverge as children become aware that public regard favors boys over girls. Thus, we would predict that affective and conceptual components of implicit attitudes would be concordant among boys, but discordant among girls, such that implicit affective processes favor girls, but conceptual processes show more ambivalence or favor boys. An analogous pattern is seen in adult studies of implicit racial attitudes, with ambivalent implicit preferences among members of the disadvantaged group. On average, White Americans show a moderate-to-strong preference for White faces over Black faces, whereas African Americans tend to show a neutral and potentially ambivalent preference for White versus Black faces (Nosek et al., 2007).

With increases in the strength and complexity of their semantic processing, our theoretical analysis predicts the emergence of adult-like implicit stereotyping effects for children in middle childhood (ages 7 to 9). With increasing exposure to cultural influences and media, such as television, movies, and the news, the content of children's stereotypes should begin to converge with those of adults (Devine, 1989; also Correll, Park, Judd, \& Wittenbrink, 2002). Indeed, American children have been shown to associate males with the math stereotype in an Implicit Association Test by around age 7 (Cvencek, Meltzoff, \& Greenwald, 2011). In contrast to implicit stereotypes, implicit attitudes are known to not simply reflect societal influences (Devine, Plant, Amodio, Harmon-Jones, \& Vance, 2002; Olson \& Fazio, 2004), and research has demonstrated that implicit stereotypes and attitudes are often uncorrelated and function independently (Amodio \& Devine, 2006). Therefore, it is possible that boys and girls in middle childhood should possess similar implicit stereotypes, in both strength and content (e.g., Rudman et al., 2001), yet diverge in their implicit affective associations, favoring their respective ingroup. Indeed, implicit gender associations in adults find that both men and women's implicit stereotypes about leadership and competence favor men, whereas their implicit stereotypes about communality and warmth favor women (see Rudman \& Glick, 2008).

To summarize, the transition observed in many girls from PFD to tomboyism should mark important developments in implicit gender associations and their relations to explicit attitudes and beliefs. In particular, younger children's implicit associations should be more strongly influenced by affective processes than by higher-level conceptual processes. However, as girls enter middle childhood and begin to second-guess their love of pink and frilly clothing (due to changes in gender representations and public regard), we expect to observe implicit gender stereotype effects and conceptual evaluations that favor boys. These implicit conceptual associations may conflict with girls' implicit affective preferences that favor their own group, and they may also begin to diverge from their more nuanced explicit attitudes and beliefs. Interestingly, this pattern of divergence is expected to be strongest among the girls who show the more extreme changes from PFD to tomboyism. This theoretical analysis suggests an interesting and informative program of future research on the development of gender attitudes and beliefs. 


\section{Discussion}

\section{Limitations and future directions}

At this point, we must note some limitations with respect to our argument. First, the processes being emphasized in the present paper represent a form of 'self-socialization,' in which children's motivations to engage in identity-relevant behaviors depend jointly on changes in social-cognitive structures and the social information available to these structures (Martin, Ruble, \& Szkrybalo, 2002). However we acknowledge that identity-relevant shifts are also at least partly influenced by changes in social, environmental, and cultural factors (Bussey \& Bandura, 1999; Higgins \& Parsons-Eccles, 1983). For example, parents with egalitarian goals may try to mitigate the influence of gender stereotypes on their children, and this gender socialization process seems likely to increase with age.

Second, one might argue that the consequences of gender status disparities may exist largely in the future for children, rather than reflect status differences experienced by children in the present. For example, girls generally outperform boys in the classroom in elementary school (Dwyer \& Johnson, 1997; Hartley \& Sutton, 2011). However, children are avid consumers of the media, which predominantly portrays boys and men as leaders and in other high-status roles (Ruble et al., 2006). Recent research suggests that the amount of TV viewing is associated with greater awareness of male-female status disparities, in children as young as 4 years of age (Halim et al., forthcoming). Thus, understanding gender status hierarchies may not require the ability to project oneself into the future to have an effect.

Third, our predictions focus on an identity shift that may be seen only in a subset of girls. Indeed, not all girls shift toward more masculine interests. Given the general socialcognitive changes at this time, why might this be? We speculate that girls experience simultaneous pressures to be typical as well as unique, and that different girls balance these simultaneous forces in different ways. Moreover, among adults, awareness of discrimination toward one's group has been associated with increased collective identification (e.g., the rejection-identification model, Branscombe, Schmitt, \& Harvey, 1999). It would be interesting in future research to investigate whether some girls in middle childhood might react to an awareness of status differences and gender discrimination with increased gender identification.

Finally, there is not yet longitudinal data to determine whether the girls who once exhibited PFD are the same girls who are later tomboys. This is an important direction for future research. However, we feel confident in our analysis of the gender identity shift given evidence of the overall normative changes that occur. As stated earlier, 74\% of girls between the ages of 3 and 4 exhibit PFD (Halim, Ruble, Lurye, forthcoming), whereas up to two-thirds of girls in middle childhood claim they are, at least, somewhat tomboys (Jannone et al., forthcoming). Thus, it makes sense that these PFD and tomboy subsets overlap.

\section{Conclusion}

After reading this article, we suspect the reader will be especially attentive to the pink and frilly fashions favored by the 4-year-old girls in one's neighborhood. One might also notice the marked lack of such fashions among the girls who are just a few years older. With this curious phenomenon as a backdrop, we examined the critical psychological, cognitive, and neural developmental changes that accompany this shift in gender identity 
among girls and considered its implications for the development of implicit attitudes and stereotypes concerning gender. In doing so, this review highlights the fruitful integration of theories on social cognition from the adult and child literatures as a means to examine issues of gender identity development and the particular ways in which intergroup biases are expressed in childhood. This curious phenomenon of young girls' fashion provides a useful platform for developing a theoretical analysis that generates several new and interesting hypotheses to be tested in future research.

\section{Acknowledgment}

We thank Kristina Zosuls for her comments on an earlier draft. We also thank our reviewers for their helpful suggestions.

\section{Short Biographies}

May Ling Halim completed her B.A. at Stanford University and is currently a doctoral student in Social Psychology at New York University. Her research examines developmental changes in gender identity, such as those associated with the 'Pink Frilly Dress' phenomenon described in this article. In other research, she studies the effects of racial and gender discrimination on psychological and biological aspects of health.

Diane N. Ruble is an Emeritus Professor of Psychology at New York University. Her interests are in the field of social and developmental psychology, particularly the development of children's knowledge about and identification with social categories, such as gender and ethnicity. She has a Ph.D. from the University of California at Los Angeles and has taught at Princeton University and University of Toronto.

David M. Amodio is an Associate Professor of Psychology and Neural Science at New York University, and the director of the NYU Social Neuroscience Laboratory. His research investigates the psychological and neural mechanisms that underlie the acquisition, expression, and regulation of racial bias, and the effects of goals and motivations on the control of perception and action in intergroup situations. He received a Ph.D. from the University of Wisconsin-Madison and completed postdoctoral training at the University of California, Los Angeles.

\section{Endnotes}

^ Correspondence address: New York University, 6 Washington Place, New York, NY10003, USA. Email: david.amodio@nyu.edu

1 Gender researchers have attempted to describe the male analog of girls' tomboyism, but note that an equally androgynous identity does not appear to exist for boys (although some use 'sissy' or 'mama's boy' as an approximation; Coyle, Trübutschek, \& Fulcher, 2011; Martin, 1989; Martin, 1990, Martin, 1995).

\section{References}

Alvarez, J. M., Ruble, D. N., \& Bolger, N. (2001). Trait understanding or evaluative reasoning? an analysis of children's behavioral predictions. Child Development, 72, 1409-1425.

Amodio, D. M. (2008). The social neuroscience of intergroup relations. European Review of Social Psychology, 19, $1-54$.

Amodio, D. M., \& Devine, P. G. (2006). Stereotyping and evaluation in implicit race bias: Evidence for independent constructs and unique effects on behavior. Journal of Personality and Social Psychology, 91, 652-661. 
Amodio, D. M., \& Frith, C. D. (2006). Meeting of minds: The medial frontal cortex and social cognition. Nature Reviews Neuroscience, 7, 268-277.

Amodio, D. M., Harmon-Jones, E., \& Devine, P. G. (2003). Individual differences in the activation and control of affective race bias as assessed by startle eyeblink responses and self-report. Journal of Personality and Social Psychology, 84, 738-753.

Amodio, D. M., \& Mendoza, S. A. (2010). Implicit intergroup bias: Cognitive, affective, and motivational underpinnings. In B. Gawronski \& B. K. Payne (Eds.), Handbook of Implicit Social Cognition (pp. 353-374). New York: Guilford.

Amodio, D. M., \& Ratner, K. G. (2011). A memory systems model of implicit social cognition. Current Directions in Psychological Science, 20, 143-148.

Ashmore, R. D., Deaux, K., \& McLaughlin-Volpe, T. (2004). An organizing framework for collective identity: Articulation and significance of multidimensionality. Psychological Bulletin, 130, 80-114.

Astington, J. W., Harris, P. L., \& Olson, D. R. (Eds.), (1988). Developing Theories of Mind. New York, NY, US: Cambridge University Press.

Bailey, E. (2008). The tyranny of pink. The Guardian, p.4.

Bailey, J. M., Bechtold, K. T., \& Berenbaum, S. A. (2002). Who are tomboys and why should we study them? Archives of Sexual Behavior, 31, 333-341.

Bates, C. (2009). Should we not dress girls in pink? BBC News Magazine. [Online]. Retrieved on 9 September 2011 from: http://news.bbc.co.uk/2/hi/uk_news/magazine/7817496.stm?.

Bem, S. L. (1993). The Lenses of Gender: Transforming the Debate on Sexual Inequality. New Haven, CT: Yale University Press.

Bigler, R. S. (1995). The role of classification skill in moderating environmental influences on children's gender stereotyping: A study of the functional use of gender in the classroom. Child Development, 66, 1072-1087.

Bigler, R. S., Arthur, A. E., Hughes, J. M., \& Patterson, M. M. (2008). The politics of race and gender: Children's perceptions of discrimination and the U.S. presidency. Analyses of Social Issues and Public Policy (ASAP), 8, 83112.

Bigler, R. S., \& Liben, L. S. (1992). Cognitive mechanisms in children's gender stereotyping: Theoretical and educational implications of a cognitive-based intervention. Child Development, 63, 1351-1363.

Branscombe, N. R., Schmitt, M. T., \& Harvey, R. D. (1999). Perceiving pervasive discrimination among AfricanAmericans: Implications for group identification and well-being. Journal of Personality and Social Psychology, 77, 135-149.

Brewer, M. B., \& Brown, R. J. (1998). Intergroup relations. In D. T. Gilbert, S. T. Fiske \& G. Lindzey (Eds.), The Handbook of Social Psychology (pp. 554-594). New York, NY, US: McGraw-Hill.

Brown, C., \& Bigler, R. S. (2004). Children's perceptions of gender discrimination. Developmental Psychology, 40, 714-726.

Burn, S. M., O’Neil, A. K., \& Nederend, S. (1996). Childhood tomboyism and adult androgyny. Sex Roles, 34, 419-428.

Bussey, K., \& Bandura, A. (1999). Social-cognitive theory of gender development and differentiation. Psychological Review, 106, 676-713.

Carpendale, J. I., \& Chandler, M. J. (1996). On the distinction between false belief understanding and subscribing to an interpretive theory of mind. Child Development, 67, 1686-1706.

Carr, C. L. (1998). Tomboy resistance and conformity: Agency in social psychological gender theory. Gender \& Society, 12, 528-553.

Casey, B. J., Galvan, A, \& Hare, T. (2005a). Changes in cerebral functional organization during cognitive development. Current Opinions in Neurobiology, 15, 239-244.

Casey, B. J., Tottenham, N., Liston, C., \& Durston, S. (2005b). Imaging the developing brain: What have we learned about cognitive development? Trends in Cognitive Science, 9, 104-110.

Correll, J., Park, B., Judd, C. M., \& Wittenbrink, B. (2002). The police officer's dilemma: Using ethnicity to disambiguate potentially threatening individuals. Journal of Personality and Social Psychology, 83, 1314-1329.

Coyle, E. F., Trübutschek, D., \& Fulcher, M. (2011). Male Gender Nonconformity and Derogatory Labels: Young Adults' Attitudes About and Labels for Preschoolers. Poster presented at the Society for Research on Child Development Biennial Meeting, Montreal, Canada.

Crone, E. (2008). Het Puberende Brein. Over de Ontwikkeling van de Hersenen in de Unieke Periode van de Adolescentie. Amsterdam: Bert Bakker.

Cvencek, D., Greenwald, A. G., \& Meltzoff, A. N. (2011). Measuring implicit attitudes of 4-year-olds: The preschool implicit association test. Journal of Experimental Child Psychology, 109, 187-200.

Cvencek, D., Meltzoff, A. N., \& Greenwald, A. G. (2011). Math-gender stereotypes in elementary school. Child Development, 82, 766-779.

Dasgupta, N. (2004). Implicit ingroup favoritism, outgroup favoritism, and their behavioral manifestations. Social Justice Research, 17, 143-169. 
Deaux, K., \& LaFrance, M. (1998). Gender. In D. Gilbert, S. T. Fiske \& G. Lindzey (Eds.), Handbook of Social Psychology (4th edn.) (pp. 788-827). New York: Random House.

Devine, P. G. (1989). Prejudice and stereotypes: Their automatic and controlled components. Journal of Personality and Social Psychology, 56, 5-18.

Devine, P. G., Plant, E. A., Amodio, D. M., Harmon-Jones, E., \& Vance, S. L. (2002). The regulation of explicit and implicit race bias: The role of motivations to respond without prejudice. Journal of Personality and Social Psychology, 82, 835-848.

Dinella, L., \& Martin, C. L. (2003). Gender Stereotypes, Gender Identity, and Preferences of Self-Identified Tomboys and Traditional Girls. Paper presented at the meetings of the Society for Research in Child Development, Tampa, FL.

Dunham, Y., Baron, A. S., \& Banaji, M. R. (2006). From American city to Japanese village: A cross-cultural investigation of implicit race attitudes. Child Development, 77, 1268-1281.

Dwyer, C., \& Johnson, L. (1997). Grades, accomplishments, and correlates. In W. Willingham \& N. Cole (Eds.), Gender and Fair Assessment (pp. 127-156). Mahwah, NJ: Erlbaum.

Eckes, T., Trautner, H. M., \& Behrendt, R. (2005). Gender subgroups and intergroup perception: Adolescents' views of own-gender and other-gender groups. Journal of Social Psychology, 145, 85-111.

Eisbach, A. O. (2004). Children's developing awareness of diversity in people's trains of thought. Child Development, 75, 1694-1707.

England, D., Martin, C. L., Dinella, L. M., \& Leonard, S. A. (2011). Girly-Girls and Androgynous Girls: How Girls who Vary in Activity Gender-Typing Differ in Other Domains of Gender-Typing. Poster presented at Society for Research on Child Development Biennial Meeting. Montreal, Canada.

Fiske, S. T., \& Neuberg, S. L. (1990). A continuum of impression formation, from category-based to individuating processes: Influences of information and motivation on attention and interpretation. In M. P. Zanna (Ed.), Advances in Experimental Social Psychology (Vol. 23, pp. 1-74). New York: Academic Press.

Flavell, J. H. (1978). The development of knowledge about visual perception. In C. B. Keasey (Ed.), Nebraska Symposium on Motivation (Vol. 25, pp. 43-76). Lincoln, NE: University of Nebraska Press.

Frith, C. D., \& Frith, U. (1999). Interacting minds - a biological basis. Science, 286, 1692-1695.

Gabrieli, J. D. (1998). Cognitive neuroscience of human memory. Annual Review of Psychology, 49, 87-115.

Gallagher, H. L., Happe, F., Brunswick, N., Fletcher, P. C., Frith, U., \& Frith C. D. (2000). Reading the mind in cartoons and stories: An fMRI study of "theory of mind" in verbal and nonverbal tasks. Neuropsychologia, 38, 11-21.

Gelman, S. A., \& Taylor, M. G. (2000). Gender essentialism in cognitive development. In P. H. Miller \& E. K. Scholnick (Eds.), Developmental Psychology Through the Lenses of Feminist Theories (pp. 169-190). New York: Routledge.

Gonzalez, C., Zosuls, K. M., \& Ruble, D. N. (2010). Traits as dimensions or categories? Developmental changes in the understanding of trait terms. Developmental Psychology, 46, 1078-1088.

Gopnik, A., \& Astington, J. W. (1988). Children's understanding of representational change and its relation to the understanding of false belief and the appearance-reality distinction. Child Development, 59, 26-37.

Halim, M. L., \& Ruble, D. N. (2010). Gender identity and stereotyping in early and middle childhood. In J. Chrisler \& D. McCreary (Eds.), Handbook of Gender Research in Psychology (pp. 495-525). New York: Springer.

Halim, M. L., Ruble, D. N., Lurye, L., Greulich, F., Zosuls, K., \& Tamis-LeMonda, C. S. (forthcoming). The case of the pink frilly dress and the avoidance of all things "girly": Girls' and boys' appearance rigidity and cognitive theories of gender development.

Halim, M. L., Ruble, D. N., Tamis-LeMonda, C. S., \& Smith, A. E. (forthcoming). What do other people think about gender groups? Young children's understanding of status differences.

Hartley, B., \& Sutton, R. (April, 2011). Failing Boys: A Stereotype Threat Account of the Gender Gap in Children's Academic Performance. Poster presented at the Biennial Society for Research on Child Development, Montreal, Canada.

Heyman, G. D., \& Gelman, S. A. (1999). The use of trait labels in making psychological inferences. Child Development, 70, 604-619.

Heyman, G. D., \& Gelman, S. A. (2000). Beliefs about the origins of human psychological traits. Developmental Psychology, 36, 663-678.

Higgins, E. T., \& Parsons-Eccles, J. (1983). Social cognition and the social life of the child: Stages as subcultures. In E. T. Higgins, D. N. Ruble \& W. W. Hartup (Eds.), Social Cognition and Social Development (pp. 15-62). Cambridge, MA: Cambridge University Press.

Hornsey, M. J., \& Hogg, M. A. (2000). Assimilation and diversity: An integrative model of subgroup relations. Personality and Social Psychology Review, 4, 143-156.

Huston, A. C. (1983). Sex-typing. In E. M. Hetherington (Ed.), Handbook of Child Psychology: Socialization, Personality, and Social Development (Vol. 4, pp. 387-467). New York: Wiley.

Hyde, J. S., Rosenberg, B. G., \& Behrman, J. A. (1977). Tomboyism. Psychology of Women Quarterly, 2, 73-75.

Jannone, S., Halim, M. L., Greulich, F. K., Lurye, L. E., \& Ruble, D. N. (forthcoming). Who I am or what I do?: An analysis of tomboy meaning in children and adults. 
Jost, J. T., Banaji, M. R., \& Nosek, B. A. (2004). A decade of system justification theory: Accumulated evidence of conscious and unconscious bolstering of the status quo. Political Psychology, 25, 881-920.

Jost, J. T., Pelham, B. W., \& Carvallo, M. (2002). Non-conscious forms of system justification: Cognitive, affective, and behavioral preferences for higher status groups. Journal of Experimental Social Psychology, 38, 586-602.

Lalonde, C. E., \& Chandler, M. J. (2002). Children's understanding of interpretation. New Ideas in Psychology. Special Issue: Folk Epistemology, 20, 163-198.

Lane, K. A., Mitchell, J. P., \& Banaji, M. R. (2005). Me and my group: Cultural status can disrupt cognitive consistency. Social Cognition, 23, 353-386.

Liben, L. S., Bigler, R. S., \& Krogh, H. R. (2001). Pink and blue collar jobs: Children's judgments of job status and job aspirations in relation to sex of worker. Journal of Experimental Child Psychology, 79, 346-363.

Liu, D., Sabbagh, M. S., Gehring, W. J., \& Wellman, H. M. (2009). Neural correlates of children's theory of mind development. Child Development, 80, 318-326.

Maccoby, E. E. (1998). The Two Sexes: Growing up Apart, Coming Together. Cambridge, MA, US: Belknap Press/Harvard University Press.

Martin, C. L. (1989). Children's use of gender-related information in making social judgments. Developmental Psychology, 25, 80-88.

Martin, C. L. (1990). Attitudes and expectations about children with nontraditional and traditional gender roles. Sex Roles, 22, 151-166.

Martin, C. L. (1995). Stereotypes about children with traditional and nontraditional gender roles. Sex Roles, 33, 1112.

Martin, C. L., \& Ruble, D. N. (2009). Patterns of gender development. Annual Review of Psychology, 61, 353-381.

Martin, C. L., Ruble, D. N., \& Szkrybalo, J. (2002). Cognitive theories of early gender development. Psychological Bulletin, 128, 903-933.

Martin, C. L., Wood, C. H., \& Little, J. K. (1990). The development of gender stereotype components. Child Development, 61, 1891-1904.

Masangkay, Z. S., McCluskey, K. A., McIntre, C. W., Sims-Knight, J., Vaughn, B. E., \& Flavell, J. H. (1974). The early development of inferences about the visual percepts of others. Child Development, 45, 357-366.

McHale, S. M., Shanahan, L., Updegraff, K. A., Crouter, A. C., \& Booth, A. (2004). Developmental and individual differences in girls' sex-typed activities in middle childhood and adolescence. Child Development, 75, 15751593.

Miller, C. F., Lurye, L. E., Zosuls, K. M., \& Ruble, D. N. (2009). Accessibility of gender stereotypes domains: Developmental and gender differences in children. Sex Roles, 60, 870-881.

Moretti, M. M., \& Higgins, E. T. (1999). Own versus other standpoints in self-regulation: Developmental antecedents and functional consequences. Review of General Psychology, 3, 188-223.

Morgan, B. L. (1998). A three generational study of tomboy behavior. Sex Roles, 39, 787-800.

Neff, K. D., Cooper, C. E., \& Woodruff, A. L. (2007). Children's and adolescents' developing perceptions of gender inequality. Social Development, 16, 682-699.

Nosek, B. A., Smyth, F. L., Hansen, J. J., Devos, T., Lindner, N. M., Ranganath, K. A. et al. (2007). Pervasiveness and correlates of implicit attitudes and stereotypes. European Review of Social Psychology, 18, 36-88.

Noseworthy, C. M., \& Lott, A. J. (1984). The cognitive organization of gender-stereotypic categories. Personality and Social Psychology Bulletin, 10, 474-481.

Olson, K. R., \& Dweck, C. S. (2008). A blueprint for social cognitive development. Perspectives on Psychological Science, 3, 193-202.

Olson, M. A., \& Fazio, R. H. (2004). Reducing the Influence of Extrapersonal Associations on the Implicit Association Test: Personalizing the IAT. Journal of Personality and Social Psychology, 86, 653-667.

Orenstein, P. (2010). Cinderella ate my Daughter. New York: Harper.

Paechter, C., \& Clark, S. (2007). Who are tomboys and how do we recognise them? Women's Studies International Forum, 30, 342-354.

Phelps, E. A., O’Connor, K. J., Cunningham, W. A., Funayama, E. S., Gatenby, J. C., Gore, J. C. et al. (2000). Performance on indirect measures of race evaluation predicts amygdala activation. Journal of Cognitive Neuroscience, 12, 729-738.

Piaget, J. (1965). The Child's Conception of Number. New York: Norton.

Plumb, P., \& Cowan, G. (1984). A developmental study of destereotyping and androgynous activity preferences of tomboys, nontomboys, and males. Sex Roles, 10, 703-712.

Pomerantz, E. M., \& Newman, L. S. (2000). Looking in on children: Using developmental psychology as a tool for hypothesis testing and model building in social psychology. Personality and Social Psychology Review, 4, 300316.

Powlishta, K. K, Serbin, L. A., Doyle, A., \& White, D. R. (1994). Gender, ethnic, and body type biases: The generality of prejudice in childhood. Developmental Psychology, 30, 526-536.

Richards, Z., \& Hewstone, M. (2001). Subtyping and subgrouping: Processes for the prevention and promotion of stereotype change. Personality and Social Psychology Review, 5, 52-73. 
Ross, H. S., Recchia, H. E., \& Carpendale, J. I. M. (2005). Making sense of divergent interpretations of conflict and developing an interpretive understanding of mind. Journal of Cognition and Development, 6, 571-592.

Ruble, D. N., \& Goodnow, J. (1998). Social development from a lifespan perspective. In D. Gilbert, S. Fiske \& G. Lindzey (Eds.), Handbook of Social Psychology (pp. 741-787). New York: McGraw-Hill.

Ruble, D. N., Lurye, L. E., \& Zosuls, K. M. (2007a). Pink frilly dresses (PFD) and early gender identity. Princeton Report on Knowledge (P-ROK), 2.

Ruble, D. N., Martin, C., \& Berenbaum, S. (2006). Gender development. In N. Eisenberg (Ed.), Handbook of Child Psychology: Vol. 3, Personality and Social Development (6th edn). (pp. 858-932). New York: Wiley.

Ruble, D. N., \& Martin, C. L. (1998). Gender development. In W. Damon \& N. Eisenberg (Eds.), Handbook of Child Psychology, 5th edn.: Vol 3. Social, Emotional, and Personality Development. (pp. 933-1016). Hoboken, NJ, US: John Wiley \& Sons Inc.

Ruble, D. N., Taylor, L. J., Cyphers, L., Greulich, F. K., Lurye, L. E., \& Shrout, P. E. (2007b). The role of gender constancy in early gender development. Child Development, 78, 1121-1136.

Rudman, L. A., Feinberg, J. M., \& Fairchild, K. (2002). Minority members' implicit attitudes: Ingroup bias as a function of group status. Social Cognition, 20, 294-320.

Rudman, L. A., \& Glick, P. (2008). The Social Psychology of Gender: How Power and Intimacy Shape Gender Relations. New York: Guilford.

Rudman, L. A., Greenwald, A. G., \& McGhee, D. E. (2001). Implicit self-concept and evaluative implicit gender stereotypes: Self and ingroup share desirable traits. Personality \& Social Psychology Bulletin, 27, 1164-1178.

Sandberg, D. E., \& Meyer-Bahlburg, H. F. L. (1994). Variability in middle childhood play behavior: Effects of gender, age, and family background. Archives of Sexual Behavior, 23, 645-663.

Saxe, R., Carey, S., \& Kanwisher, N. (2004). Understanding other minds: Linking developmental psychology and functional neuroimaging. Annual Review of Psychology, 55, 87-124.

Sellers, R. M., Smith, M. A., Shelton, J. N., Rowley, S. A. J., \& Chavous, T. M. (1998). Multidimensional model of racial identity: A reconceptualization of African American racial identity. Personality and Social Psychology Review, 2, 18-39.

Sowell, E. R., Thompson, P. M., Leonard, C. M., Welcome, S. E., Kan, E., \& Toga, A. W. (2004). Longitudinal mapping of cortical thickness and brain growth in normal children. Journal of Neuroscience, 24, 8223-8231.

Steele, J. (2003). Children's gender stereotypes about math: The role of stereotype stratification. Journal of Applied Social Psychology, 33, 2587-2606.

Szkrybalo, J., \& Ruble, D. N. (1999). "God made me a girl”: Gender constancy judgments and explanations revisited. Developmental Psychology, 35, 392-402.

Tajfel, H., \& Turner, J. C. (1979). An Integrative Theory of Intergroup Conflict. In W. G. Austin \& S. Worchel (Eds.), The Social Psychology of Intergroup Relations (pp. 33-47). Monterey, CA: Brooks-Cole.

Tajfel, H., \& Turner, J. C. (1986). The social identity theory of inter-group behavior. In S. Worchel \& L. W. Austin (Eds.), Psychology of Intergroup Relations (pp. 7-24). Chigago: Nelson-Hall.

Teig, S., \& Susskind, J. E. (2008). Truck driver or nurse? the impact of gender roles and occupational status on children's occupational preferences. Sex Roles, 58, 848-863.

Tobin, D. D., Menon, M., Menon, M., Spatta, B. C., Hodges, E. V. E., \& Perry, D. G. (2010). The intrapsychics of gender: A model of self-socialization. Psychological Review, 117, 601-622.

Trautner, H. M., Ruble, D. N., Cyphers, L., Kirsten, B., Behrendt, R., \& Hartmann, P. (2005). Rigidity and flexibility of gender stereotypes in childhood: Developmental or differential. Infant and Child Development, 14, 365-380.

Verkuyten, M., Kinket, B., \& van der Wielen, C. (1997). Preadolescents' understanding of ethnic discrimination. Journal of Genetic Psychology, 158, 97-112.

Vonk, R., \& Ashmore, R. D. (2003). Thinking about gender types: Cognitive organization of female and male types. British Journal of Social Psychology, 42, 257-280.

Vonk, R., \& Olde-Monnikhof, M. (1998). Gender subgroups: Intergroup bias within the sexes. European Journal of Social Psychology, 28, 37-47.

Wainryb, C., Shaw, L. A., Langley, M., Cottam, K., \& Lewis, R. (2004). Children's thinking about diversity of belief in the early school years: Judgments of relativism, tolerance, and disagreeing persons. Child Development, 75, 687-703.

Wellman, H. M., Cross, D., \& Watson, J. (2001). Meta-analysis of theory-of-mind development: The truth about false belief. Child Development, 72, 655-684.

Wiley, S., Perkins, K., \& Deaux, K. (2008). Through the looking glass: Ethnic and generational patterns of immigrant identity. International Journal of Intercultural Relations, 32, 385-398.

Yee, M., \& Brown, R. (1994). The development of gender differentiation in young children. British Journal of Social Psychology, 33, 183-196.

Zosuls, K. M., Martin, C. L., Ruble, D. N., Miller, C. F., Gaertner, B. M., \& England, D. E. (2011). "It's not that we hate you": Understanding children's gender attitudes and expectancies about peer relationships. British Journal of Developmental Psychology, 29, 288-304. 